\title{
Deformation Analysis and Simulation of the Cup-Shaped Flexspline for Harmonic Drive Using in Aerocrafts
}

\author{
Li Zu, Aihua Yin, Yanyang Sun, Y. L. Wang, Yi Ou, and Yi Liang
}

\begin{abstract}
The harmonic gears used in servo drive systems of aerocrafts have the features of over loading and working for a short time. They are required to be smaller and lighter. Theoretical research and finite element analysis are given to the deformation characteristic of the flexible gear for the harmonic drive. This paper studies the initial deformation of the flexible gear, and compares with the result of finite element analysis. Overload is applied to the flexible gear, and by using ABAQUS FEA software, the distortions on the flexspline can be found. The research results provide theoretical references for improving load capacity of harmonic drive and designing this type of harmonic drive.
\end{abstract}

Index Terms-Harmonic drive, flexspline, deformation, overload, finite element analysis.

\section{INTRODUCTION}

With the continuous development of space technology, servo drive systems of aerocrafts are expected to have characteristics such as compactness, light-in-weight property, high bearing capability, excellent dynamic characteristic and reliability. Applied in servo drive systems, the harmonic gears have superiorities in several terms[1]-[3]: high transmission ratio in a limited space which helps to decrease the system in size and in weight, small backlash which contributes to precision and stability, good performance under an oil-free and high temperature condition.

In a large-loaded short-time running aerocraft, the failure modes of harmonic gears differ from those in conventional conditions. The failure of flexspline performs as break caused by low static strength instead of by fatigue fracture, it also performs as engagement failure caused by excessive interference. Both practical and theoretical research demonstrated that flexspline, which is closely related to the stress state caused by its deformation, is the weakest part of harmonic gear drive. Based on a theoretical research, this study will take the example of cup-shaped harmonic drive device and study the deformation of non-loaded and

Manuscript received on November 2, 2014; revised on August 22, 2015 This work was supported by the National Natural Science Foundation of China (51105206), also supported by the National Science and Technology Major Project of the Ministry of Science and Technology of China (2012ZX04002021), Fundamental Research Funds for the Central Universities (30920130111001)

The authors are with Nanjing University of Science and Technology, 210094, Nanjing, China (e-mail: zuli@njust.edu.cn, yah1004@163.com). overloaded flexspline.

\section{THEORETICAL ANALYSIS OF FLEXSPLINE DEFORMATION}

A cup-shaped flexspline with double wave is jointed to the output shaft by bolts at its bottom shown in Fig. 1. The wave generator consists of an elliptical cam and a flexible bearing.

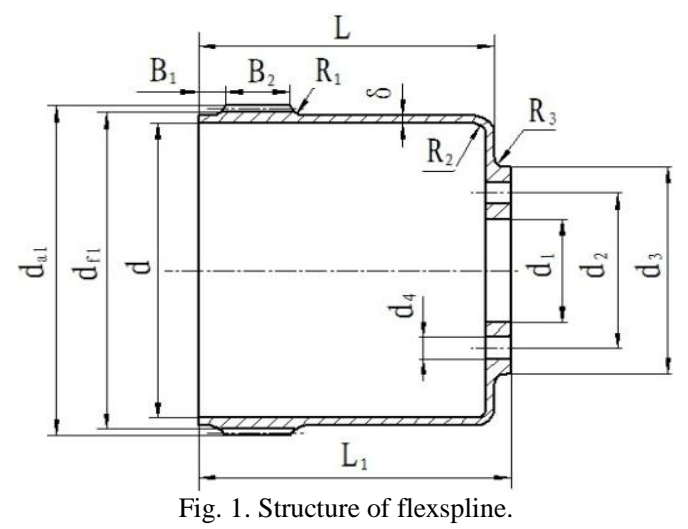

\section{A. Initial Deformation of the Flexspline}

The initial deformation is the deformation of a non-loaded flexspline when it is assembled with a wave generator. This initial deformation is closely related to the loading capacity of the harmonic gear drive, as well as the form of the wave generator. A wave generator with elliptical cam is suitable for high precision field condition and chosen for this research. It will optimize the engagement between rigid gear and flexspline, which contributes to a good stress distributing state and loading capacity of flexspline.

In the deformation process, the initial curve, which theoretically is the isometric curve of the ellipse, can be presented by radial displacement $\omega$ and circumferential displacement $v$.To present the relation between $\beta$ and $\omega_{(\beta)}$, a cosine calculation model as below is used instead of elementary function which could be far more complex [4].

$$
\omega_{(\beta)}=\omega_{0} \cos 2 \beta
$$

$\omega_{0}$ is an important parameter for harmonic gear drive design, which is the maximum radial deformation. $\beta$ is the rotating angle. With this model, the radial deformations are identical on both macro and minor axis. Fig. 2 compares the radial displacements obtained from this model with those from theoretical model.

According to Fig. 2, these two curves correspond well with each other in the interval of $\left(45^{\circ}, 135^{\circ}\right)$ and $\left(225^{\circ}, 315^{\circ}\right)$. When $\beta=90^{\circ}$, significant errors appear with a max of $0.006 \mathrm{~mm}(1 \%)$, which shows that errors augment around the 
minor axis. It should be stated that if the circular spline is manufactured at a 6 class precision in basic shaft system, its outer diameter tolerance is then $0.019 \mathrm{~mm}$ which is far greater than the maximum error between the blue and red lines.

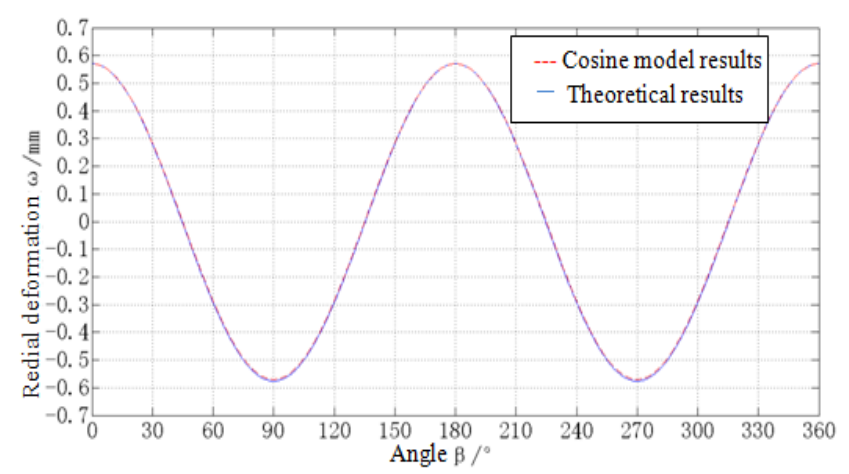

Fig. 2. Radial displacements obtained from two methods.

The cosine calculation model is such simple that the maximum radial deformation appears in minor axis and macro axis direction while the maximum axial deformation, half of the radical deformation, appears in the direction at a $45^{\circ}$ angle with the minor or macro axis. The cup part is assumed to have constantly straight generatrix and round cup bottom. Based on the half no-moment theory of cylindrical shell, (1) can be obtained to describe the radial axial and circumferential deformation [5].

$$
\left\{\begin{array}{c}
\omega_{(\beta, z)}=\frac{z}{l} \omega_{0} \cos 2 \beta \\
v_{(\beta, z)}=-\frac{z}{2 l} \omega_{0} \sin 2 \beta
\end{array}\right.
$$

$z$ in (1) is the distance between the studied section and flexspline cup bottom; $l$ is the distance between the loaded plane and cup bottom. It is showed in (1) that $\omega$ and $v$ change in a linear fashion along the axis direction.

\section{B. Deformation of the Flexspline When Bearing Load}

Distortion shows in Fig. 3 arises when the flexspline is under load. The flexspline approaches the wave generator in the regions $A B$ and $A^{\prime} B^{\prime}$ while it detaches itself from the generator in $A B^{\prime}$ and $A^{\prime} B$. Such distortion is caused by flexibility of the wave generator, clearances between different components and extension of the flexspline.

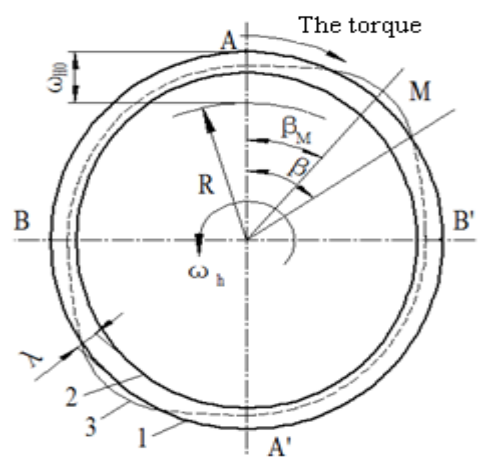

Fig. 3. Flexspline distortion.

The wave generator rotates counterclockwise at a speed of $\omega_{h}$ while the torque is in the clockwise direction. Points $A$ and $A^{\prime}$ are on the macro axis, $B$ and $B^{\prime}$ are on the minor axis and $\mathrm{M}$ is the point where appears the maximum distortion. $R$ stands for the radius of flexspline midline before deformation and $\lambda$ stands for clearances between components.

Line 1 represents the initial shape of flexspline in the ideal situation where it has no clearance or deformation. The corresponding nominal radical displacement and circumferential deformation are $\omega_{H}$ and $v_{H}$ respectively. Line 2 represents the outline of the wave generator when the clearance $\lambda$ exists evenly along the contour. Lastly, the line 3 is the initial curve of the flexspline as it is under load.

\section{Deformations in the Region $A B$ [5]}

In this region, deformations can be presented as below, where $v_{p}$ represents the circumferential deformation caused by flexspline extension. $\lambda_{\mathrm{K} 0}$ is the radical displacement when $\beta=0^{\circ}$.

$$
\left\{\begin{array}{l}
\omega=\omega_{H}-\lambda-\lambda_{k 0} \cos \beta \\
v=v_{H}+\lambda \beta+\lambda_{k 0} \sin \beta+v_{p}
\end{array}\right.
$$

\section{1) Deformations in the region $A B^{\prime}$}

$A M$ is approximately a constant radius arc. $\omega$ and $v$ are given, respectively, as

$$
\left\{\begin{array}{l}
\omega=\omega_{H 0}-\lambda-\lambda_{k 0} \\
v=-\left(\omega_{H 0}-\lambda-\lambda_{k 0}\right) \beta
\end{array}\right.
$$

In the region $M B^{\prime}$, deformations are more complex:

$$
\left\{\begin{array}{l}
\omega=\left(\omega_{H 0}-\lambda-\lambda_{k 0}\right)\left[B_{1}\left(\frac{\pi}{2}-\beta\right) \cos \beta+B_{2} \sin \beta+C\right] \\
v=-\left(\omega_{H 0}-\lambda-\lambda_{k 0}\right)\left[B_{1}\left(\frac{\pi}{2}-\beta\right) \sin \beta-\left(B_{1}+B_{2}\right) \cos \beta+C \beta+C_{1}\right]
\end{array}\right.
$$

Parameters $B_{1}, B_{2}, \mathrm{C}, \mathrm{C}_{1}, \lambda_{\mathrm{K} 0}, \lambda$ and $v_{p}$ are complex. As it is not practical to get accurate results out from (2) (3) and (4), finite elements software can be used.

\section{FINITE ELEMENT ANALYSIS OF FLEXSPLINE DEFORMATIONS}

Theoretical solutions have been given previously. However, more factors should be taken in to consideration in practical use, which can be simulated and analyzed by finite element software.

\section{A. Modeling}

The wave generator is simplified as a rigid thin-wall ring whose inner and outer surfaces are both equidistant curves of the elliptical cam wave generator. The wave generator is 'cut into' two halves, an upper part and a lower part, which move respectively upwards and downwards for a distance. This helps to simulate the process of wave generator being installed into the flexspline. A torque is applied on the inner surface of the flange to simulate the load on flexspline. The 
finite element models are shown in Fig. 4.

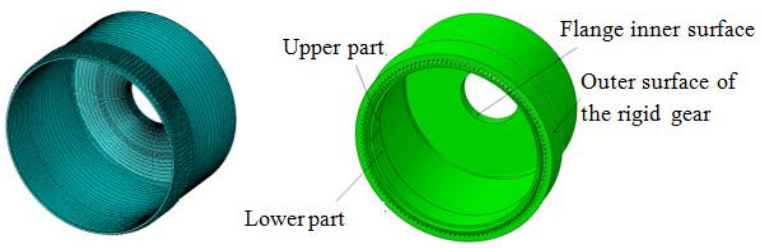

(a) Flexspline Fig. 4. Finite element models of harmonic drive.

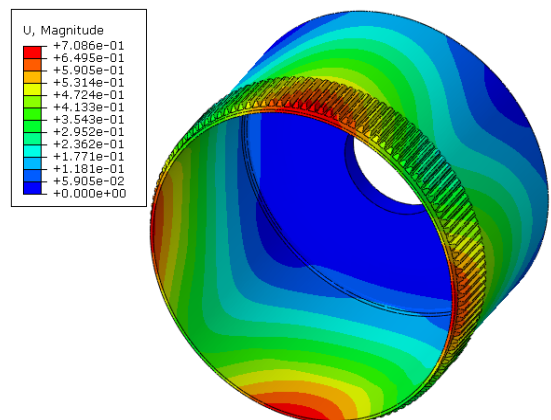

(a) Flexspline deformation

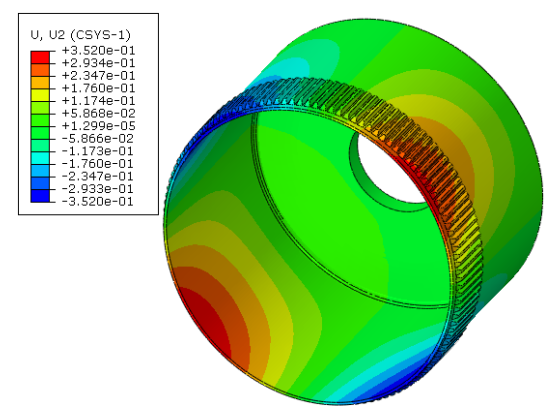

(a) Circumferential deformation

Fig. 5. Pictures of flexspline initial deformation.

\section{B. Initial Deformation of the Flexspline}

Fig. 5 presents the flexspline deformation after the wave generator's installation. When flexspline is non-loaded, the maximum radical deformation appears on the macro and minor axes of the wave generator; the maximum circumferential deformation, about half the large of the maximum radical deformation, is at an angle of 45 degrees with the macro/minor axis; the axial deformation is changeless along the flexspline axis. These results correspond well with (1).

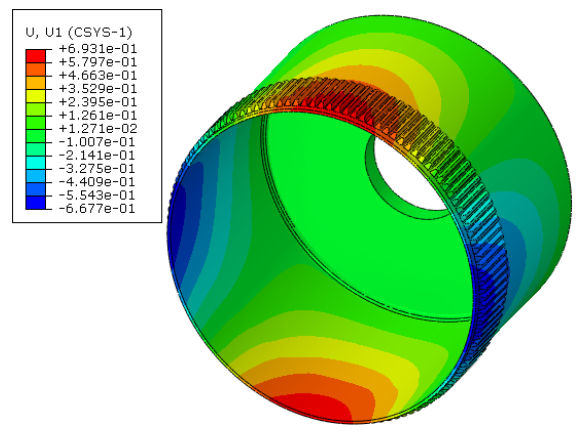

(b) Radial deformation

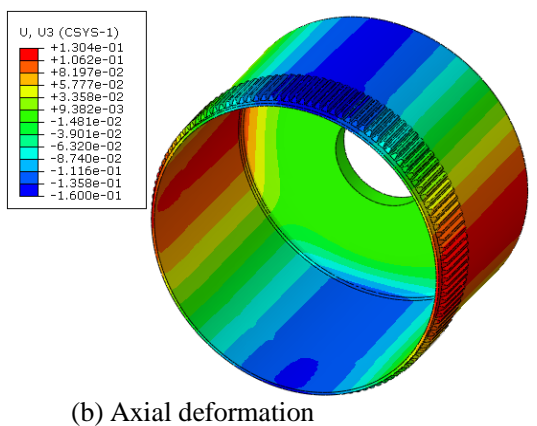

(b) Axial deformation

element analysis.

It is shown in Fig. 6(a) that there are certain errors around the macro and minor axes while the rest parts present very well. The theoretical macro-axis deformation is $\omega=\omega_{0}=0.57 \mathrm{~mm}$, while result of finite element analysis is $0.5921 \mathrm{~mm}$ with an error of $3.9 \%$. The theoretical minor-axis deformation is $\omega_{\left(90^{\circ}\right)}=-0.57 \mathrm{~mm}$ comparing to finite element analysis result $-0.5534 \mathrm{~mm}$ with an error of $2.9 \%$. The cause is that wave generator is assumed to be closely attached to the flexspline inner wall to calculate the theoretical primitive curve. However, the width of the generator cannot be ignored in reality. Because of the limit from cup bottom, deformations along axes are not even so that the generatrix inclines. There is a distance between the inner wall of the flexspline and the bearing outer ring, which verifies with $\beta$.

Fig. 6(b) compares the circumferential deformation given by theoretical research and finite element analysis. These two results tally well with each other, except a certain errors at 45 degrees from macro/minor axis with a maximum error less than $0.6 \%$.

As the errors between two methods are within an acceptable range and the deformations correspond well, (1) can be taken as the deformation regularity of the flexspline loaded section. where $z=l$, different deformations can be theoretically. Fig. 6 compares the results of theoretical research and finite 


\section{Deformation of Flexspline When Bearing Load}

The chosen flexspline has an inner diameter of $\phi 72 \mathrm{~mm}$ and a rated load of $90 \mathrm{Nm}$, which is suitable for long-time running harmonic gear drive. However, for high-loaded

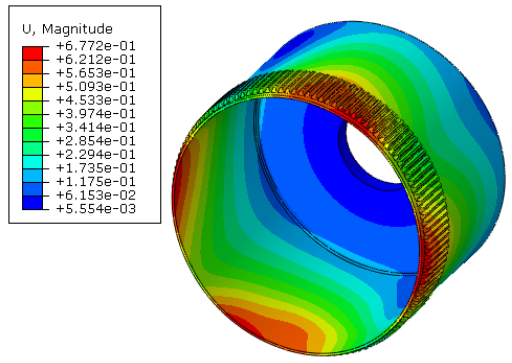

(a) Flexspline deformation.
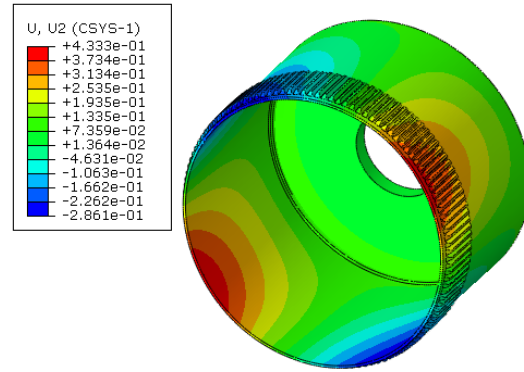

(a) Circumferential deformation

Fig. 7. Pictures of loaded flexspline deformation. short-time running ones, for example aerocrafts, the real load is usually greater than rated load. So a torque $T=250 \mathrm{Nm}$, which is 3 times the rated load. Pictures of loaded flexspline deformation are shown in Fig. 7.

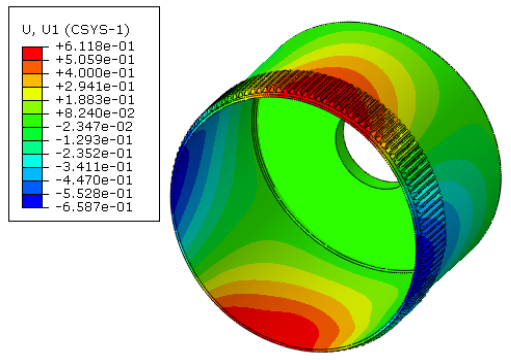

(b) Radial deformation.

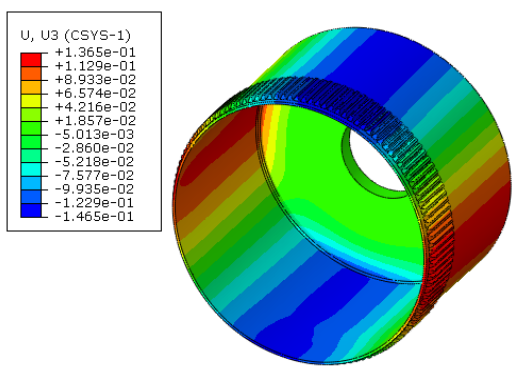

(b) Axial deformation
To study the deformation change of flexspline on its loaded section, Fig. 8 presents the radical and circumferential deformations in both loaded (represented by red lines) and non-loaded (represented by blue lines) situation.

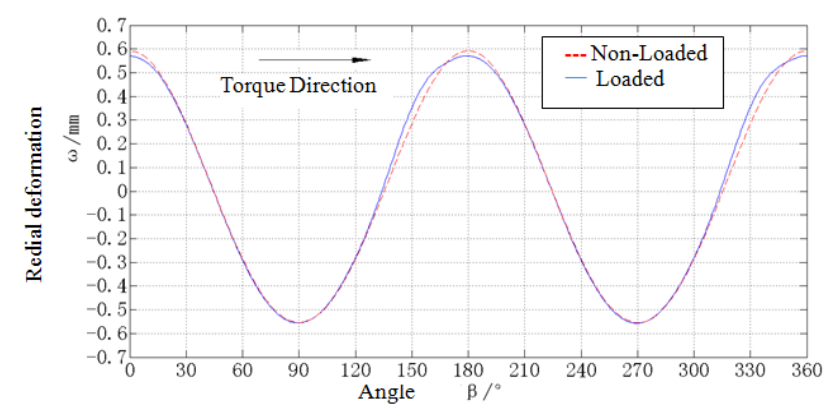

(a) Redial deformation

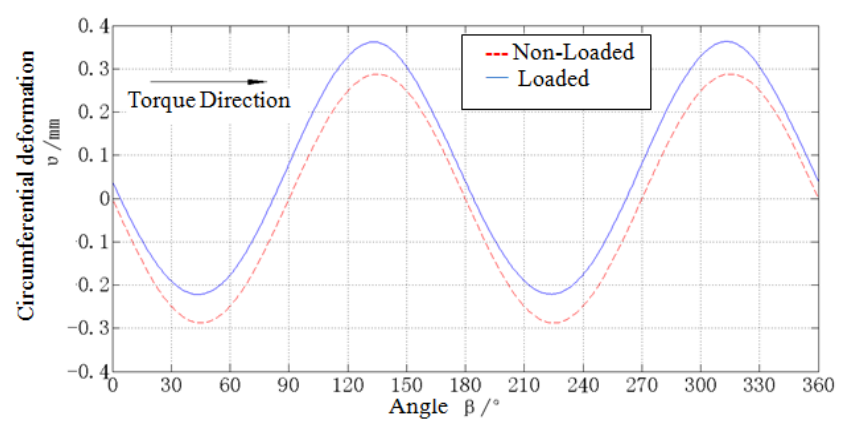

(b) Circumferential deformation

Fig. 8. Comparison results of non-loaded and loaded deformation of flexspline.

In Fig. 8(a), the blue line moves to the left side of the red line in the region of $\beta=130^{\circ}-170^{\circ}$. The reason is that the radical deformation here gets bigger under load and the flexspline detaches itself from the wave generator, which is called distortion as mentioned before.

Fig. 8(b) shows that the blue line moves up a little from the red one. Since the positive direction of $v$ is the same as the direction of the torque, then it can be concluded that the flexspline warps due to the torque, no matter for its rim or bottom, they all distort a certain angle.

In summary, when flexspline is under load, distortion appears so that the inner wall of the flexspline is closely attached to the wave generator in the engaging-in region and the radical deformation decreases. In the contrary, the flexspline is detached form the wave generator in the engaging-out region and the radical deformation increases.

The cup part turns a certain angle leading the circumferential deformation curve to move up a little from the one unloaded.

\section{CONCLUSION}

Harmonic drive used in aerocrafts has features of short running time and large load. The initial deformation is related to stress distribution and load capacity. This paper studies the deformations of a cup-shaped flexspline in the harmonic drive, which lead to the following research results:

1) By analysis of the initial deformation of a harmonic gear drive equipped with an elliptical cam wave generator, a cosine calculation model is used to present the theoretical deformation of a flexspline, errors are within the tolerances of element parts.

2) By using finite element software to simulate the harmonic drive assembly, deformation analysis of the unloaded flexspline can be done. According to the comparison between theoretical study and finite element analysis, results of these two methods are found to be 
similar, and the theoretical study is proved to be correct.

3) Finite element analysis of a short-time running flexspline which is loaded by 3 times of the rated load has been done. It shows that distortion arises as the flexspline is under load. The deformation augments in the engaging-out region and forms a hunch-up.

This paper could provide theoretical references for the study of flexspline for harmonic drive using in aerocrafts, also for the optimization design of related parts.

\section{REFERENCES}

[1] M. Yamamoto, M. Iwasaki, M. Kainuma, Y. Okitsu, K. Yuki, K. Sasaki, and T. Yajima, "Compensation for synchronous component of angular transmission errors in harmonic drive gearings," in Proc. 2010 11th IEEE International Workshop on Advanced Motion Control, 2010, pp. 361-365.

[2] M. R. Johnson, R. Gehling, and R. Head. "Failure of harmonic gears during verification of a two-axis gimbal for the mars reconnaissance orbiter spacecraft," in Proc. the 38th Aerospace Mechanisms Symposium, Langley Research Center, pp. 37-51, May 17-19, 2006.

[3] R. Clark, S. CaIverley, K. Atallah, D. Howe et al., "Design, analysis and realization of a novel magnetic harmonic gear," in Proc. 2008 International Conf. on Electrical Machines, 2008, pp. 1-7.

[4] W. Shi, Q. Zhang, and X. Li, "The research about deformation and stress of flexspline in harmonic drive based on abaqus," Mechanical Engineer, no. 6, pp. 44-47, 2010.

[5] М. Н. Иванов, Harmonic Gear Drive, Beijing National Defence Industry Press, 1987

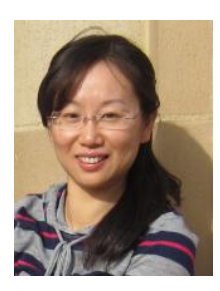

Li Zu was born in Nanjing, Jiangsu Province, China on June 19, 1977. In July 1999, she received the bachelor's degree in Suzhou University, Su Zhou Jiang Su Province, China in mechanical design and theory. In July 2005, she received the doctor's degree in Nanjing University of Science and Technology, Nanjing, Jiangsu Province, China in mechanical and electronic Engineering.

She has worked in Nanjing University of Science and Technology as a teacher for 9 years from July 2005. Now she is an associate professor in the Dept. of Mechanical Design and Automation. From August 2012 to January 2013, She was a visiting scholar in California State University, Northridge, USA. Now she is working on National Natural Science Foundation Project - "Studies of the Load-bearing Performance of Precision Harmonic Gear within Abnormal Conditions and Design" and National Science and Technology Major Project - "Common Technology of Rolling Elements in the CNC Machine and Testing, Test Equipment Development Platform". She has published 1) L. Zu, L. Zhang, and H. k. Wang, "Optimization design of the lawn mowing vehicle's blade based on aerodynamics," Advanced Materials Research, pp. 231-237, 2011. 2) L. Zu, Y. Liang, and M. L. Song, "Study and design of an inchworm-1ike micro-robot walking mechanism," Lecture Notes in Electrical Engineering vol. 123 , pp. 69-78, 2011. Her research area covers mechanical design, precision drive technology and intelligent machines.

Prof. $\mathrm{Zu}$ is a member of the Association of Mechanical Engineering of Nanjing, Jiang Su Province, China.

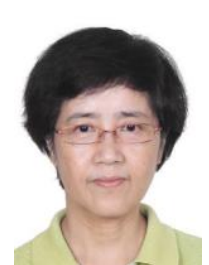

Aihua Yin was born in Shanghai, China on October 4, 1953. In July 1978, Aihua Yin graduated from Donghua University, Shanghai, China, majoring in electrical engineering and automation.

She has worked in Nanjing University of Science and Technology as a teacher for more than 30 years since August 1978. Now she is an associate professor in Department of Mechanical and Electronic Engineering. Her research interests are in the areas of mechatronics technology, robot system design, and precision measure and control technology. Her major research projects include "multifunctional mobile robot", "intelligent service robot" and "ball screw dynamic error measurement system".

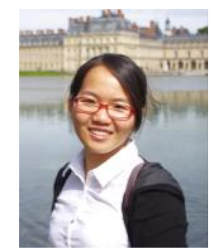

Yanyang Sun was born in Yancheng, China on April 15, 1991. In June 2013, Sun received the bachelor's degree in Nanjing University of Science and Technology, Jiang Su Province, China in mechanical engineering and automation. In September 2014, Sun received the engineer's degree in Ecole des Mines de Nantes, France in control engineering and industrial information technology.

In 2013, she did an internship as an engineer assistant in Mecacorp company in France. In 2014, she was a business process assistant at Renault Techno Centre in Paris, France. She is currently a master's student of Nanjing University of Science and Technology, China, majoring in mechanical engineering.

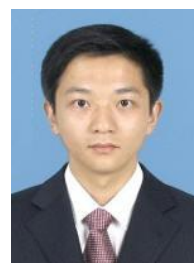

Yulin Wang was born in Nanjing, Jiangsu Province, China on December 26, 1981. In July 2003, Yulin Wang received The bachelor's degree in Nanjing University of Aeronautics and Astronautics, Nanjing, Jiangsu Province, China in mechanical manufacture and automation. In July 2009, Yulin Wang received the doctor's degree in Shanghai Jiao Tong University, Shanghai, China in mechanical and electronic engineering.

He has worked in Nanjing University of Science and Technology as a teacher for 5 years from December 2009. Now he is an associate professor in DEPT. of Mechanical and Electronic Engineering. From September 2013 to September 2014, he was a visiting scholar in Purdue University, Indiana, USA. His research interests are in the areas of hard turning technology, FEA, robot and manipulator, and precision measure and control technology.

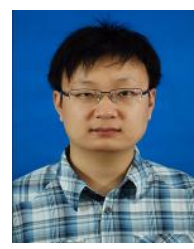

Yi Ou was born in Shaanxi, P.R. China, on August 28, 1982. Yi Ou earned his bachelor's and master's degree of mechanical engineering in Nanjing University of Science and Technology, Jiangsu province, P.R. China, in 2006 and 2012, respectively.

He has been teaching and researching in the field of dynamic performance analysis, precision test and life/reliability analysis for function units of machine tools, especially the rolling components combined with rigid-flexible coupling multi-body mechanical theory, contact mechanics, etc., dynamic performance analysis and optimization design for rolling components are carried out. His major field of study is mechanical design, Ground mobile robot technology, measurement and control technology of mechanical system.

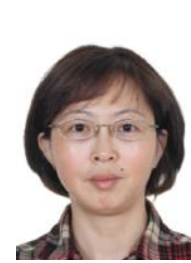

Yi Liang was born in Shaanxi, P.R. China, on August 5 , 1974. Yi Liang earned her bachelor and master's degrees of mechanical engineering in Nanjing University of Science and Technology, Jiangsu province, P.R. China, in 1991 and 1998, respectively. Her major field of study is mechanical design and optimization.

She has been teaching and researching in the field of mechanical engineering since 1998 in Nanjing University of Science and Technology. The courses she taught are mechanisms and machine theory, machine elements, and mechanical optimization for the undergraduates and postgraduates. Associate professor Yi Liang focuses on the research of mechanical design and finite element analysis of machine elements. Two of her published articles are listed here: "Transmission momentary efficiency based on the D“Alembert -Lagrange equation for involutes gear," Chinese Journal of Mechanical Engineering, vol. 2, pp. 272-275, Dec. 2004; "Finite element analysis of shell of mower cutter head," Journal of Machine Design, vol. 21, pp. 253-254, Jun. 2005. Now Yi is interested in the optimization design and accuracy analysis of rolling linear guide ways. 